\title{
Psychosocial Counselling in Nepal: Perspectives of Counsellors and Beneficiaries
}

\author{
Mark J. Jordans • Annalise S. Keen • Hima Pradhan • \\ Wietse A. Tol
}

Published online: 9 February 2007

(C) Springer Science + Business Media, LLC 2007

\begin{abstract}
The aims of this qualitative study were (1) to add to the understanding of the growing field of psychosocial counselling in Nepal, and (2) gather concrete points for improvement of services. Semi-structured interviews were conducted with clients $(n=34)$, para-professional counsellors $(n=26)$ and managers $(n=23)$ of organizations in which psychosocial counselling was taking place. The main findings were that stakeholders generally presented a positive view of the significance and supportive function of psychosocial counselling, while providing useful suggestions for improvement. Matters of ongoing training and supervision, confidentiality and integration of counselling within mainstream care provision need to be addressed and potentially adapted. Implications for other non-Western countries with little mental health resources are discussed.
\end{abstract}

Keywords Psychosocial counselling $\cdot$ Nepal $\cdot$ Counsellor training $\cdot$ Counselling services

\section{Introduction}

This article concerns the emerging field of psychosocial counselling within Nepali society, as part of rehabilitation services for children and adults who have been affected by human rights abuses and community violence. The study aimed at exploring the perceptions of counsellors, clients (direct beneficiaries) and managers of child care institutions (indirect beneficiaries) on issues of relevance and applicability of counselling within nongovernmental organizations working for these target groups.

Nepal is a South-Asian Hindu Kingdom, landlocked between India and China and is home to many ethnic groups. The majority of its 23 million population resides in the countryside. The

M. J. Jordans $(\bowtie) \cdot$ W. A. Tol

Public Health and Research Department, HealthNet-TPO, Tolstraat 127,

Amsterdam 1074 VJ, Netherlands

e-mail: mjordans@healthnettpo.org

A. S. Keen $\cdot$ H. Pradhan

Center for Victims of Torture, Nepal,

Bansbari 3, Kathmandu, Nepal 
main economic activity is agriculture and the majority (82\%) survives on less then two dollars a day (Singh, Dahal, \& Mills, 2005). Serious human rights violations have escalated since the Communist Party of Nepal (Maoists) launched a "people's war" against the Government forces in 1996, leading to a climate of intense fear (Human Rights Watch, 2004; Singh et al., 2005). This is taking place against a background of other people-made disasters afflicting Nepal, such as trafficking for sexual exploitation and other forms of child labour.

Mental health receives little attention in Nepal. Of the $3 \%$ of the national budget that the Government has allocated for health, approximately $1 \%$ is spent on mental health. Traditional and religious healing methods are commonly practiced. There is no mental health act and the National Mental Health Policy formulated in 1997 is yet to become fully operational (Regmi, Pokharel, Ojha, Pradhan, \& Chapagain, 2004). Western mental health practices have started to get increasing attention, most notably through psychiatric services (there are currently around two dozen psychiatrists) and psychosocial counselling.

Still, the state of counselling in Nepal is largely meagre. Training courses are typically short, do not include clinical practice and more often than not are given by expatriate trainers new to the cultural setting. Counselling is habitually misunderstood, resulting often in judgmental and uninformed implementation, and sometimes in incorrect practices. The state of counselling is further complicated because of the random application of the word 'counsellor' to anyone doing 'social work' within an NGO setting (Kohrt, 2006).

To compensate, a practice-oriented and skill-based training approach was developed to increase the number of well trained counsellors in Nepal. These courses were run jointly by the Center for Victims of Torture (CVICT - a non-governmental organisation providing rehabilitation services to victims of torture and other human rights abuses) and the Transcultural Psychosocial Organization (TPO — an international organization working on developing and researching psychosocial care systems in [post-] conflict settings). Two courses were developed - (1) a paraprofessional five month course for students with minimal educational backgrounds and (2) a 1 year post-graduate diploma course in counselling affiliated with Purbhanchal University, the country's second largest university. At the time of the study no other extensive counselling courses were offered in Nepal. Each course has been separately financed by the donor agency that commissioned the course in order to integrate psychosocial intervention capacity within ongoing programs of that donor agency.

The paraprofessional course, involving five months duration, starts with a 3-week core training period followed by several cycles of alternated supervised practical placements and further training sessions for increasingly advanced skills and topics. The distribution of training hours is approximately $400 \mathrm{~h}$ of classroom learning, $150 \mathrm{~h}$ of clinical supervision, $350 \mathrm{~h}$ of practice within a real-life setting and $10 \mathrm{~h}$ of personal therapy. The last component refers to participants going through counseling sessions themselves, aiming to provide a model for intervention as well as to create personal awareness and self reflection (Jordans, Sharma, Tol, \& van Ommeren, 2002). Details of the training program have been published elsewhere (Jordans et al., 2002; Jordans, Tol, Sharma, \& van Ommeren, 2003). With this approach, more then 130 counsellors have been trained over the past five years. Except for two batches of psychologists $(n=12)$, all trained counsellors have minimal educational background (i.e., mainly high school level, with a few college-level participants), hence the indication paraprofessional.

There are five core-defining features of the training approach, which are widely accepted in Western programs but are still largely ignored in training programs in most of South Asia (Frederick, 2002). First, courses are medium to long term, recognizing that learning about complex and intricate helping processes requires more than just a brief period. Second, a training of trainers model is not used. This is seen as not appropriate at this point as it 
requires advanced clinical experience in order to effectively train others. Third, the approach is skills-based, emphasizing micro counselling skills (A. E. Ivey \& M. Ivey, 1999), extensive role plays and practical placements. Fourth, there is a stress on clinical supervision and practical personal therapy as tools to connect newly acquired skills to an actual service-provision setting. Fifth, cultural sensitivity is emphasised. Working with Western-oriented therapeutic assumptions in a non-Western setting requires adaptations to increase cultural relevance. In this case, adaptation started with a reflection on existing healing methods, the nature of therapeutic relationships, and the use of therapeutic concepts such as locus of control, introspection and abstraction (Tol, Jordans, Regmi, \& Sharma, 2005). This has yielded changes in intervention strategies including (a) a shift of focus from intra-psychic or cognitive processes to concrete problem-solving, (b) application of microskills and concrete counselling techniques (e.g., relaxation exercises), and (c) the inclusion of a thorough psycho-education component.

The training programs use manuals that have been translated and pre-tested in the Nepali language (de Jong \& Clarke, 1996; Jordans, 2002; Jordans, 2003) and are conducted by experienced Nepali trainers - psychologists who received the first of the intensive training courses by CVICT and TPO and subsequently gained clinical experience and further training. The training courses are seen as compatible with international guidelines (Weine et al., 2002) and include topics such as understanding counselling concepts and process, the understanding of mental health problems, and the application of counselling skills and specific intervention strategies. Through role-plays, lectures, experiential learning and group work, the trainees learn skills specific for targeted beneficiaries as well as generic concepts such as working with coping strategies, symptom management techniques (e.g., relaxation), psycho-education and strengthening of existing resources.

Counselling practiced as a result of the above-mentioned training approach (Jordans et al., 2003) combines client-centered and problem-solving approaches. It includes non-specific therapeutic elements, such as empathy, intercultural sensitivity and basic communication skills, with structured steps that aim to reduce both stressor-induced symptoms of distress as well as, whenever possible, problem situations (Egan, 1998; A. E. Ivey \& M. Ivey, 1999). For application within a non-Western setting, basic concepts from medical anthropology (e.g., Kleinman, Eisenberg, \& Good, 1978), such as working with clients' illness experiences, explanatory models and idioms of distress, have been included (van Ommeren, Sharma, Prasain, \& Poudyal, 2002) and the level of the intervention has been adapted for paraprofessional use, following a public mental health approach. The latter involves a shift of focus from providing specialized psychiatric mental health care with a biomedical focus, to providing an easy-access level of care targeting common distress that links with existing formal and informal care structures. It is argued that psychosocial counselling has a place in a spectrum of psychosocial services for those more severely affected by organized violence and human rights abuse. We follow the Psychosocial Working Group (2002) in their description of 'psychosocial', which encompasses psychological well-being and/or mental health (emotional, cognitive and behavioral stability of the individual); it emphasizes social ecology (consisting of the wider community connections, social support networks and other existing healing resources) and; it entails working from the significance and appropriateness given by existing culture and values.

Although the implementation of this approach has been positively evaluated through independent programmatic assessments (Frederick, 2002; Slugget, 2003) as well as empirical effectiveness research (de Jong, Komproe, \& O'Connell, 2004; Tol, Komproe, Jordans, Thapa, de Jong, \& Sharma, submitted), little is known about the opinions and perspectives of direct and indirect beneficiaries and counsellors. 
This study focused on the applicability and relevance of counselling as perceived by local actors. A qualitative study design, using semi-structured interviews, was chosen, aiming to gather perspectives on needs for, satisfaction with, understanding of, and attitude towards counselling.

\section{Methodology}

\section{Respondents}

The study focused on a group of 30 counsellors, who were selected because they had been trained with funding from the donor that commissioned this study (International Labour Organization, ILO) as a means to better understand the application of actual services after completion of the training course. The counsellors had received training one to two years previous to the study; $26(87 \%)$ were contacted and agreed to participate. Of the interviewed counsellors, $77 \%$ were female and 23\% male with ages ranging from 21 to 42 .

Clients were sampled through a snowball procedure; counsellors were asked to identify former clients and approach them for possible participation in the study. The counsellors were also asked to help arrange contact between their managers and the researchers. The target client population were children and youth in, or rescued from, high-risk situations (e.g., child trafficking; child porters; street children; domestic child labourers; orphans). The interviewed clients $(n=34)$ had received psychosocial care from the counsellors as a result of expressed and/or observed psychosocial problems. Twenty-six (76\%) were female, eight $(24 \%)$ male. The average age was $18.6(\mathrm{SD}=7.81)$ with $24(71 \%)$ respondents 18 years or less and $85 \%$ still in school. See Table I for demographic characteristics.

Twenty-three managers ( $70 \%$ female; $30 \%$ male) of 17 rehabilitation and care institutions for victims of human rights abuses and violence were interviewed. The functions of the interviewed management staff ranged from directors $(n=6)$, to coordinator of programs and residential centers ("shelters") $(n=11)$, to administrative officers $(n=5)$. These 17 organizations, within which counselling was integrated, represent a set of non-governmental organizations providing institutional or community based care to the above mentioned client population, both within Kathmandu and other (some remotely located) districts (Jumla, Jhapa, Kaski, Danusha). Ten (38\%) out of the 23 interviews were conducted outside Kathmandu.

\section{Procedure}

Interviews with the managers and counsellors were conducted mainly in English with Nepali translation, while interviews with clients were conducted entirely in Nepali. Most interviews were conducted by a team consisting of an experienced Nepali psychologist/ counsellor (HP) familiar with the training approach and a medical student from Harvard

Table I Demographic Information of Clients

\begin{tabular}{|c|c|c|c|c|}
\hline & Gender & Mean age & Religion & Education \\
\hline \multirow[t]{5}{*}{ Clients $(n=34)$} & Female $76 \%$ & $18.6(\mathrm{SD}=7.81)$ & Hindu $73 \%$ & Attending school $85 \%$ \\
\hline & Male $24 \%$ & & Buddhist 9\% & Not attending school $15 \%$ \\
\hline & & & Christian $6 \%$ & \\
\hline & & & Muslim 6\% & \\
\hline & & & None or Other $6 \%$ & \\
\hline
\end{tabular}


University joining the team for the purpose of the study (AK). Interviews in the more remote districts were conducted by a Dutch clinical psychologist (WT-living and working in Nepal for several years) together with another Nepali psychologist/counsellor. Interviews lasted from one to one and a half hours.

Informed written consent was obtained from all participants and confidentiality was assured and maintained throughout. The objectives of the research and its methodology were explained to potential study participants, and they were assured that non participation would not in any way result in negative consequences regarding treatment or otherwise. Any questions or concerns about the study were addressed during the interview and participants were given contact information and advised to contact the researchers with any concerns.

\section{Instruments}

All interviews were done with the use of semi-structured interview formats. Care was taken to avoid socially desirable response tendencies, through avoiding leading questions and emphasizing the need for honest answers to be able to improve services. Most questions were open-ended, but some questions were asked in a closed format to obtain specific information - on levels of perceived cultural relevance and satisfaction with received services.

The interview format for clients consisted of two parts: (a) demographics and (b) questions related to the intervention (problems experienced, client's understanding of the process of counselling, opinion on counselling received, satisfaction with counselling and cultural relevance of counselling). The interviews with counsellors and managers were less structured and consisted of themes. For the counsellors these themes were (a) evaluation of and perspectives on training received, (b) questions focusing on psychosocial counselling (felt competence as a counsellor, skills used, type of services delivered), and (c) organizational aspects (role of management, integration with other services and role in the organization). The themes for manager interviews were (a) attitude/opinions towards counselling, (b) opinion on needs for counselling, (c) implementation issues (integration with other services, difficulties experienced in implementation).

\section{Analysis}

The researchers followed steps for qualitative data analysis as described in Varkevisser, Pathmanthan, and Brownlee (2004). Content analysis was done on the notes taken during interviews. As is common in analysis of qualitative data collected for small respondent groups, the analysis consisted firstly of categorizing answers of respondents together. These categorized responses were subsequently inspected for common themes in the content on which the description of results was based. Quantitative data were entered and analyzed with the help of SPSS (version 10 for PC), while word processing software (Microsoft Word 2000 for PC) was used for the categorization of (translated) qualitative responses.

\section{Results}

Clients' perspectives

\section{Expressed problems and received care}

The 34 clients who were interviewed seemed to have presented for counselling with mild to severe psychosocial problems, based on the clinical impression of the treating counsellor. No 
diagnostic interview was conducted as part of the study. Clients stated that their problems included, in order of frequency: anxiety, aggression, fear, difficulties with reintegration into society and family life and stigmatization, other family issues, loneliness, trauma, suicidality, insomnia, domination by others, guilt, and inability to concentrate.

The average number of counselling sessions that clients received was $4.8(\mathrm{SD}=4.6)$, with the least being one session and the most being three sessions monthly for one year. It is important to note that some clients were still in the process of receiving counselling at the time of interview.

\section{Opinion of counselling}

Most of the clients interviewed seemed to have a good understanding of psychosocial counselling. They described it as a process of providing relief by working with a counsellor with whom they were able to share and/or solve their personal problems. Most of the clients interviewed stated that psychosocial counselling was a worthwhile service that was culturally appropriate, with $91 \%$ of the clients explaining that counselling fitted perfectly or well within their cultural setting ("the term is new but this sort of counselling in essence has been happening for a long time in Nepal"), see Table II. Overall, clients reported to be satisfied with counselling services offered, with $91 \%$ responding that they were very satisfied or mostly satisfied with services received. As open expressions of emotion are not always appropriate in Nepali culture, several clients expressed that counselling fulfilled their need to have someone listen and understand their problems and feelings, with people they saw overall as trustworthy, understanding and considerate. Many clients also declared that they appreciated that counselling seemed effective at helping them solve their problems; for example, by raising their self-confidence, helping them to become less worried or improving relationships. Some clients discussed how they enjoyed problem-solving with counsellors ("We discussed the advantages and disadvantages of each decision. When you are alone, you don't think about those things. In counselling you can").

Though clients were generally very satisfied with the service overall, a significant proportion (27\%) expressed a lack of attention to specific needs (see Table II—notably for medication, entertainment, material support, home visits, vocational training courses, educational support or a healthy family environment ("It's good to share my feelings and problems; but in the end I got nothing; I had wanted to get training") - reflecting some discrepancy between service provision and experienced needs.

Table II Overview of Clients' Responses on Cultural Appropriateness, Satisfaction of Needs and Satisfaction about the Services $(\mathrm{In} \%)$

\begin{tabular}{llllll}
\hline & Fits perfectly & Fits well & Fits OK & Fits a little & Does not fit at all \\
\hline $\begin{array}{l}\text { Cultural } \\
\text { appropriateness }\end{array}$ & 82 & 9 & 3 & 6 & 0 \\
\hline & Very satisfied & Mostly satisfied & $\begin{array}{c}\text { Indifferent/ } \\
\text { mildly satisfied }\end{array}$ & $\begin{array}{c}\text { Quite } \\
\text { dissatisfied }\end{array}$ \\
\hline $\begin{array}{l}\text { Satisfaction with } \\
\text { services }\end{array}$ & 71 & 20 & 6 & 3 & \\
\hline
\end{tabular}

\begin{tabular}{lllll}
\hline & All needs met & Most need met & Only few needs met & No needs met \\
\hline Satisfaction of needs & 38 & 35 & 21 & 6 \\
\hline
\end{tabular}




\section{Confidentiality}

Confidentiality came forward as an issue of some contention and confusion. The majority of the clients stated that confidentiality was maintained throughout the counselling process. However, some mentioned that confidentiality was not maintained, resulting in reduced satisfaction and willingness to share. Others simply were worried that confidentiality might not be maintained. Some specific suggestions were presented, for example that counselling should take place in quieter areas where confidentiality was more likely to be maintained.

\section{Counsellors' perspectives}

\section{A new profession}

For most of the counsellors, the training was their first exposure to psychosocial care in general, providing a radical new way of thinking about assisting people. Several counsellors stated that the course not only helped them learn new counselling skills but led to profound personal development, including being able to communicate more effectively and feeling more confident. One counsellor mentioned that this sort of training lends legitimacy to her work. Practical placements were found to be valuable, primarily if specifically attuned to the training needs. Overwhelmingly, almost all counsellors expressed a need for more advanced training as well as regular supervision by trained counsellors and opportunities to share and network with other counsellors.

The majority of trained counsellors were working as counsellors, albeit in addition to performing other duties within their organizations. For some these multiple responsibilities were compatible with the counselling activities (e.g., conducting training courses or awareness programs), but for others they were distracting (e.g., maintaining office logistics or administrative work) or even incompatible (e.g., management functions). For those who saw them as distracting or incompatible, the dual functions were perceived as limiting due to time restraints or confusing due to conflicts of interest, and generally reflective of a lack of management's prioritization of psychosocial services.

\section{Service provision}

Only slightly more than half of the counsellors interviewed felt competent as counsellors, many of them expressing that organizational difficulties, uncooperative clients and insufficient (follow-up) training limited their abilities. Counsellors stated overwhelmingly that micro counselling skills were the most essential means to provide effective support. In addition, empathy, relaxation, challenging and brainstorming were mentioned more often than other skills as being used by the counsellors.

The counsellors saw a wide variety of clients, including, in order of decreasing number of responses, trafficking survivors, domestic violence survivors, rape survivors, conflictaffected people, street children, people with HIV/AIDS, (domestic) child labourers, sexually abused children, community child labourers and destitute people (see Table III).

\section{Integration within the existing care system}

The majority of counsellors reported that management at their organizations were supportive and counselling was integrated into the overall program of their organization. 
Table III Summary of Responses

\begin{tabular}{|c|c|}
\hline $\begin{array}{l}\text { Respondents } \\
\text { (number) }\end{array}$ & Responses \\
\hline $\begin{array}{l}\text { Clients } \\
\qquad(n=34)\end{array}$ & $\begin{array}{l}\text { - Clients interviewed were predominantly Hindu women/girls who had attended school } \\
\text { - Clients had many different problem presentations including anxiety, fear, aggression, } \\
\text { suicidality, social reintegration issues and family related concerns } \\
\text { - Clients were satisfied with counselling services, while a majority expressed specific unmet } \\
\text { expectations } \\
\text { - Clients thought counselling services were culturally appropriate } \\
\text { - Clients received on average } 4.8 \text { counselling sessions }(\mathrm{SD}=4.6) \text { at the time of study }\end{array}$ \\
\hline $\begin{array}{l}\text { Counsellors } \\
\quad(n=26)\end{array}$ & $\begin{array}{l}\text { - The training program provided a new perspective of care and lead to profound personal } \\
\text { development, but was deemed too short } \\
\text { - Maintaining confidentiality was found to be an issue of contention } \\
\text { - About half of the counsellors felt competent while the other half did not } \\
\text { - The vast majority of counsellors trained were currently working as counsellors, sometimes } \\
\text { limited by multiple responsibilities } \\
\text { - Counsellors worked with a variety of clients including trafficking survivors, domestic } \\
\text { violence survivors, rape survivors, conflict-affected children, and street children } \\
\text { - There is a need for ongoing training and regular supervision and networking with colleagues }\end{array}$ \\
\hline $\begin{array}{c}\text { Managers } \\
\quad(n=23)\end{array}$ & $\begin{array}{l}\text { - All managers stated that counselling was implemented in their organizations and most } \\
\text { explained that it was well integrated into the organization and indicated for most clients } \\
\text { - Difficulties in implementation included the mobile, uncooperative nature of clients, lack } \\
\text { of money and time, need for more counsellors, need for more training, supervision and } \\
\text { follow up for counsellors, need for more awareness and a more systematic approach } \\
\text { - Recommendations included: more networking opportunities for counsellors, selection } \\
\text { of counsellors of same ethnicity/gender, and awareness raising for other non-counselling } \\
\text { staff }\end{array}$ \\
\hline
\end{tabular}

Of those counsellors who were having difficulties, the most frequent problems mentioned were that the management wanted counselling to provide immediate results, staff and managers did not really understand counselling and that managers were not providing needed resources. Not all had clear job descriptions that specifically included, or made reference to, providing counselling services.

\section{Managers' perspectives}

\section{Understanding of counselling}

Most of the managers seemed to have a good general understanding of psychosocial counselling, ("counsellors don't give suggestions or advice-clients find these out themselves. The counsellor simply facilitates and shows them the way") and reported positive changes in clients as a result of it. Some expressed criticism ("counselling takes too long to be useful; clients are not always cooperative and sometimes even lie; counselling is too easy on clients"), giving the impression that there remains confusion about the exact meaning of the work among managers (perhaps unsurprisingly, as psychosocial care is a new approach for many). However, others expressed criticism that revealed some important challenges; for example that some counsellors were "too aloof, serious, and isolated", and that "in psychosocial counselling the focus is too much on the psychological component and not enough on the social". 


\section{Integration and implementation within organization}

All managers interviewed stated that psychosocial counselling as taught by the described training approach fitted well with the mandate of their organizations. Most stated it was a crucial part of the services they provide, and was indicated for their target client groups. A few explained that counselling was only indicated for some of their clients, and only one manager stated it was rarely indicated.

While a few managers stated that there were no difficulties in implementing counselling within their organizations, the vast majority explained that they faced obstacles. Not having enough time to allocate to do counselling well, not having enough money, and the uncooperative, mobile, diverse or reluctant nature of clients were very frequently mentioned concerns. It was also mentioned that there simply were not enough counsellors to do all the counselling that is needed. Although less frequently mentioned, it is important to note that some managers described obstacles that were reflective of their own role in the service integration process; for example, the many roles counsellors must play in their organizations, not being able to provide a proper environment for them, one counsellor being threatened when trying to intervene in domestic disputes, resistance by other staff and managers, the stigma related to counselling, employing male counsellors where female counsellors would be more appropriate for their target populations and the isolated nature of counsellors within the organization.

\section{Recommendations}

The managers had recommendations regarding the improvement of counselling. First and foremost, most of the managers mentioned that counsellors needed more advanced target population-specific training. Many managers stated that the counsellors needed more clinical supervision, more follow-up from expert/senior counsellors in general, and more opportunities to network with other counsellors. Moreover, many mentioned that they would like more awareness training for their staff. In particular, several managers expressed that more counsellors were needed, especially those from the same backgrounds as their clients.

\section{Conclusion}

From the interviews a number of positive and negative features emerged. Almost all counsellors, direct and indirect beneficiaries expressed their support for psychosocial counselling as it had yielded positive changes in both clients' perceived well-being as well as attitudes and empowerment of psychosocial service delivery at large. Moreover, counselling, as an intervention, was deemed culturally relevant and acceptable.

Clients who underwent counselling sessions generally presented with mild to severe psychosocial problems (mostly issues of stigmatization, anxiety reactions, aggression, and depressive moods), and were of the opinion that the supportive and understanding role of the counsellor was helpful for them to feel reassured or assisted in problem management. On the other hand, counselling did not always match clients' expectations and needs (e.g., for material support) and several obstacles and criticisms were reported that hindered effective counselling.

For Nepal, where first steps are being made for the integration of counselling within the service provision spectrum for vulnerable populations, this study gives indications on how to continue this development. The conclusions should be seen from the perspective of a 
country where mental health has been chiefly represented by an overly medical-psychiatric model and counselling by short-term training courses without thorough clinical practice and often provided by culturally alien expatriate professionals. (1) Despite the fact that the training program was the only intensive psychosocial training program in Nepal, it was still felt to be too short and not covering some topics in enough depth, or at all. In fact, about half of the counsellors interviewed did not feel competent enough mainly because they felt they needed more training. (2) It was perceived by both the counsellors and the managers that there was a lack of needed follow-up and especially supervision, ongoing training and networking after completion of the training program. (3) More attention needs to be given to the integration of psychosocial counselling within the existing care spectrum, with this including formalizing the role of counsellors within organizations as well as further sensitization of staff to the exact meaning of counselling. This also needs to take into account that counsellors need to be selected who better represent the target populations (i.e., gender, ethnicity, etc.). While most counsellors found their managers supportive and most managers described their staff as mostly supportive of counselling, future initiatives are likely to benefit from more awareness raising in organizations where counselling takes place. (4) The issue of confidentiality came forward as an important and sensitive point, from all three perspectives. This might be explained by the collectivist nature of most ethnicities in Nepal, where privacy is regarded as less essential or less customary. Future programming, therefore, needs to discuss the function and integration of confidentiality.

Though findings from this study cannot be simply generalized to other settings, some of the implications, however, could serve as points of reflection for other countries that go through similar processes of counselling and psychosocial system development. The significance of these findings for other non-Western countries that have little psychosocial resources can be summarized as follows: (1) Counselling should ideally not be practiced as an isolated intervention, but rather within a system of care provision. The finding that psychosocial counselling does not address some important client needs indicates that linkage with other resources, including traditional and religious healing strategies, should be emphasized. This implies a need for a high level of coordination between both governmental and non-governmental services that so far has proved difficult to realize in the Nepali setting. (2) Though adaptations to the local cultural settings are central to our approach (as mentioned above) we choose not to exaggerate the cultural divide in terms of helping responses, effectively taking a middle position within the cultural relativism versus cultural universalism debate. On the question about the cultural acceptability of a new service like psychosocial counselling in Nepal, clients' answers were more affirmative than were expected. (3) Quality control and sustainability of newly trained counsellors, can only be achieved through parallel development of clinical supervision and case-management systems. (4) Rather than following a specific theoretical school of psychotherapy, it appears that a focus on micro counselling skills, concrete intervention techniques and generic therapeutic elements can make psychosocial interventions in a non-Western context like Nepal both applicable and feasible.

Though the qualitative study has yielded interesting information and valuable practical insights, some obvious limitations must be noted: (1) the sample size was small, for the client, counsellor and manager groups; (2) the design was cross-sectional in nature; (3) the sample was not selected at random but through purposive sampling, it is, therefore, not possible to generalize to wider populations in Nepal; (4) the effectiveness of counselling services was not systematically addressed; (5) as the research was undertaken by 
interviewers representing the organization that provided the training program, a socially desirable response bias might be present in clients' and managers' responses, although specific care was taken to avoid this as mentioned above.

In conclusion, this study provides an overview of the main stakeholders' perspectives of psychosocial counselling in Nepal, which has implications especially for the development and integration process of counselling. The study shows that counselling was mostly wellreceived by clients, acceptable and applicable within the Nepali setting and responsive to needs of this clientele for an understanding, empathic and good listener assisting them with a variety of psychosocial problems. At the same time it provides worthwhile suggestions on how to improve and adapt counselling and counselling training programs. Keeping in mind the limitations, this study indicates that a culturally sensitive implementation of counselling in a multi-cultural setting like Nepal is perceived by local service providers and beneficiaries as a viable way to deal with problems presented by such target groups.

Acknowledgments The researchers would like to thank those who assisted in the study and, in particular, Ram Prasad Sapkota, for assisting with conducting interviews in the more remote areas. The International Labour Organization (ILO), Nepal funded this study.

\section{References}

de Jong, J. T. V. M., \& Clarke. L. (Eds.) (1996). Mental health of refugees. Geneva: WHO/UNHCR.

de Jong, J. T. V. M., Komproe, I. H., \& O’Connell, K. A. (2004). Effectiveness and cost-effectiveness of mental health care in five low-income countries: Burundi, Cambodia, Gaza, Nepal \& Uganda. Washington DC: World Bank.

Egan, G. (1998). The skilled helper. A problem-management approach to helping (Sixth ed.). California, USA: Brooks/Cole.

Fredericks, J. (2002). Human resources development for the care of the sexually abused and sexually exploited, a resource document on training programs. In J. Fredericks (Ed.), Creating a healing environment: Psychosocial rehabilitation and occupational integration of child survivors of trafficking and other worst forms of child labour (pp. 111-154). Geneva: International Labour Organization.

Human Rights Watch (2004). Between a rock and a hard place: Civilians struggle to survive in Nepal's civil war. Available at: www.hrw.org/reports/2004/nepal1004. Accessed 29/03/2006.

Ivey, A. E., \& Ivey, M. (1999). Intentional interviewing and counseling: Facilitating client development in a multicultural society (Fourth ed.). California: Brooks/Cole.

Jordans, M. J. D. (2002). Psychosocial counselling for trafficked youth, handling the trauma of sexual exploitation.Specialized training manual. Geneva: International Labour Organization.

Jordans, M. J. D. (Ed.) (2003). Training handbook and general manual on psychosocial counselling for children in need of special protection (3rd ed.). Kathmandu: UNICEF.

Jordans, M. J. D., Sharma, B., Tol, W. A., \& Van Ommeren, M. (2002). Training of psychosocial counsellors in a non-Western context: The CVICT approach. In J. Fredericks (Ed.), Creating a healing environment: Psychosocial rehabilitation and occupational integration of child survivors of trafficking and other worst forms of child labour (pp. 165-192). Geneva: International Labour Organization.

Jordans, M. J. D., Tol, W. A., Sharma, B., \& Van Ommeren, M. (2003). Training Psychosocial counselling in Nepal: Content review of a specialized training program. Intervention: International journal of mental health, psychosocial work and counseling in areas of armed conflict, 1, 18-35.

Kleinman, A., Eisenberg, L., \& Good, B. (1978). Culture, illness and care: Clinical lessons from anthropologic and cross-cultural research. Annals of Internal Medicine, 88, 251-258.

Kohrt, B. (2006). A brief report on psychological trauma and psychosocial services in Kathmandu, Nepal. Atlanta: Emory University.

Psychosocial Working Group (2002). Psychosocial interventions in complex emergencies: A Conceptual framework. Edinburgh: Refugee Studies Center, Queen Margaret University College, Oxford: University of Oxford.

Regmi, S. K., Pokharel, A., Ojha, S. P., Pradhan, S. N., \& Chapagain, G. (2004). Nepal mental health profile. International Review of Psychiatry, 16, 142-149. 
Singh, S., Dahal, K., \& Mills, E. (2005). Nepal's war on human rights: A summit higher than Everest. International Journal for Equity in Health, 4, 1-25.

Slugget, C. (2003). Mapping of psychosocial support for girls and boys affected by child sexual abuse. Four countries in South and Central Asia. Kathmandu: Save the Children Sweden Denmark.

Tol, W. A., Jordans, M. J. D., Regmi, S., \& Sharma, B. (2005). Cultural challenges to psychosocial counseling in Nepal. Transcultural Psychiatry, 42, 317-333.

Tol, W. A., Komproe, I. Jordans, M. J. D., Thapa, S. B., Sharma, B., \& de Jong, J. T. V. M. Brief multidisciplinary treatment for torture survivors in Nepal: A naturalistic effectiveness study. Submitted.

Van Ommeren, M., Sharma, B., Prasain, D., \& Poudyal, B. N. (2002). Addressing human rights violations. In J. T. V. M. de Jong (Ed.), Trauma, war, and violence: Public mental health in socio-cultural context (pp. 259-283). New York: Plenum.

Varkevisser, C. M., Pathmanathan, I., \& Brownlee, A. (2004). Designing and conducting health system research projects. Vol. 2: Data analyses and report writing. Amsterdam: Royal Tropical Institute.

Weine, S., Danieli, Y., Silove, D., Van Ommeren, M., Fairbank, J., \& Saul, J. for the Task Force on International Trauma Training (2002). Guidelines for international training in mental health and psychosocial interventions for trauma-exposed populations in clinical and community settings. Psychiatry, 65, 156-164. 